Theories \& Applications, the International Edition

Printed Version : (ISSN 2090-5262)

Online Version : (ISSN 2090-5270)

November 2014, Volume 4, No. 3 Pages (136 - 145)

\title{
Effect of Motor Improvisation on Adiponectin and Osteocalcin Hormones in Elderly Obese Women.
}

\section{Dr. Eman Wagih Mohamed}

Lecturer at Dept. of Dancing and Motor Rhythm Training ,Faculty of Physical Education for Girls, Cairo, Egypt.

\begin{abstract}
The researcher carried out the current study to identify the effect of motor improvisation on percentage of concentration of adiponectin and osteocalcin hormones, some related physiological variables represented by pulse, systolic and diastolic blood pressures, vital capacity, percentage of fats, body weight, body mass index (BMI) and some physical variables represented by muscular strength and vertebral column flexibility in elderly obese women. The research used the experimental method of one experimental group design and the sample included (10) women of (65 to 75) years and of medium obesity after excluding (5) women one of them was suffering from discard in mitral valve and another had difficulty in breathing. After making the pre-measurements a woman was suffered from a broken, another passed away and the other leaved the house with her relatives. The average weight of the sample individuals was $86.30 \mathrm{~kg}$. The experiment was applied to the sample for (12) weeks by four lessons/week and each lesson lasted (90) min. After applying the motor improvisation program, the researcher has previously selected for this age as it was varied (walk, run, jump, turns, regressive movements and swings). It was suitable for this age that tends to express internal emotions together with varied and inter esting music that helps encourage and suspense elderly people in performing exercises without feeling boredom and to ease tension featuring this age as well as discharging potential power freely. The results showed that motor improvisation was positively effective on adiponectin and osteocalcin hormones by $9.77 \%$ and $17.75 \%$, pulse by $3.77 \%$, systolic and diastolic blood pressures by $6.30 \%$ and $1.86 \%$, vital capacity by $6.29 \%$, percentage of body fat, and body weight by $27.85 \%$ and $10.63 \%$ the level of blood cholesterol by $22.05 \%$, muscular strength and forward vertebral column flexibility by $65.09 \%$ and $200.47 \%$ in elderly obese women as there were significant differences between the pre and post-measurements in physiological and physical variables. Also, there were percentages of improvement indicating that the motor improvisation program included several constituents contributed to find out such differences in favor of the post-measurements.
\end{abstract}

Introduction

A ging is a naturally physiological process occurred in every individual and it is affected by lifestyle and several environmental and genetic factors but it is not a pathological condition. Also it is a gradual process where physiological changes occur slowly and cannot be stopped, however, its damages will be minimized if the integrated health care and right healthy habits are considered.

Afaf Abdel Monaem Darwish and Mohamed Jaber Breikaa (2000) illustrated that the process of elders began when catabolism exceeded metabolism with the result that the body was apt to several disorders such as heart diseases, sclerosis, obesity, diabetes, less secretion of some hormones i.e. melatonin being responsible for improving sleeping quality and reducing sleepless (23:15) as well as secreting adiponectin being effective on catabolism and metabolism conditions, which is a protein hormone being secreted from fat cells into the blood. Such hormone was less secreted in cases of obesity as it was proportionate reversely with obesity (70:193) (74)(75)(76)

Human body needs motion either to develop his biological and motor functions or to maintain it; hence, it is necessary to consider sport that plays its role in this field to maintain the biology and activity of the body. Performing physical activity regularly features high health that enables the body to sustain life demands in work or in life easily as well as protecting the body from several diseases $(1: 151)$.

Improvisation stimulates the free movement in the form of instant physical responses resulting from the stimulus and motive, where composition and performance are included simultaneously. It stands on subjectivity and personal imagination of the improvisator (18:83-84)(2:38)(4:107)

In this study the researcher turned to motor improvisation to contribute to improving health status and physical fitness of elderly women particularly obese women to maintain their health and to protect them from aging diseases through physical activity represented by expressive movements they do not need to learn. So improvisation is the primitive form of expression the woman uses every day and momentary. It is a basic human feature and the means we need in our daily movement. Physical activity is considered as a complementary treatment for some diseases such as obesity, hypertension, excess of blood fat and cholesterol and low bone density.

Obesity has become an unfavorable matter for men or women even for children and elders (24:167).

Meanwhile, obesity has been related to many chronic diseases. However, it has not considered as a primary hazard factor itself, obesity becomes now an independent hazard factor. It makes man apt to suffer from hypertension and excess of blood fat and cholesterol (17:45)(59:194-197). 
Obesity and its related problems play an important role in clinical medicine. However, adiponectin is secreted in blood is reversely proportionate to obesity (38)(43)(48).

Adiponectin was outlined for the first time and it was discovered in the middle of nineties by four different work teams that used all available means to define it descriptively (57:451).

Adiponectin is a protein hormone of nature and is synthesized in the white fatty tissue. It was called "Adipo" by Leng in 1996 (49:1069).

The rate of adiponectin in blood is high and ranges from 5$30 \mathrm{ug} / \mathrm{cm}$ that equals to 1000 folds of the rate of the most of other hormones such as leptin and also represents $0.01 \%$ of blood protein a6nd consequently, it is the major component of adiponectins secreted from fatty tissue (69:469)

As reported by many scientists, adiponectin reduces infection of females with several diseases because it is secreted in females with higher rate than that in male and it helps remove triglycerides (46:1756).

Previous studies showed that blood adiponectin was reversely proportionate to human bone mineral density. This relationship was clear in adults but not in children (51:2212).

Recently it has been verified that higher rate of blood adiponectin was accompanied by lower bone density and bone general weakness. Also this hormone had a unique property as it affected bone structure regardless high or low body weight ${ }_{(37) \text {. }}$

Therefore, the researcher studied osteocalcin that it is a protein hormone, is synthesized in osteoplast, helps maintain bone mineral density and is an indicator of the structure and growth of bone tissue ${ }_{(78)}$.

Osteocalcin is known as (GIA)- bone protein or $\mathrm{K}$ vitamin bonding protein with calcium and representing a main constituent of bone $(77)$

Osteocalcin is specialized in the formation of mineral tissues and is greatly synthesized by D vitamin and this process is accompanied by bone restructure and speed synostosis. Osteocalcin deficiency reflects low bone mass $(58)$.

Increasing osteocalcin in blood means increasing bone density because it plays an active role in bone metabolism and controls bone growth and formation through processes of metabolism and catabolism (39)(56)(73)(78).

Recently studies have been progressed and scientific research concluded that bone density in obese person is higher than that in non-obese person even in parts not apt to loads. Consequently, researchers conducted perspective study on a factor or specific hormone secreted from fatty cells to regulate bone metabolism. Actually the research concluded that the fatty tissue secreted several hormones of multi functions. The most important hormone in this regard was adiponectin which is secreted from cells forming bones indicating that this hormone has an important role in bone metabolism of building and demolishing (50). Some studies showed that there was a negative correlation between the level of adiponectin and bone density $(42)(50)(80)$.

Hence, the current research idea appeared that is a scientific workout to identify the effect of motor improvisation on the levels of adiponectin and osteocalcin focusing on elderly women as they need a special care in view of changes occur post menopause and consequent effects on bone density particularly in elderly obese women. In view of the reverse relationship between obesity and adiponectin secretion as the rate of secretion of adiponectin in blood in obese women is decreased but it is increased in plasma with age as indicated by some studies and consequently it effects on bone density since studies have proved that bone density in obese person was higher than that in non-obese person. Some studies verified that there was a negative correlation between the level of adiponectin and bone density, therefore, the researcher had to follow up osteocalcin concentration in blood plasma that helps keep bone mineral density and to identify some related physiological functions and some physical variables affected this age of women such as muscular strength and flexibility. The researcher selected motor improvisation in this age as it is varied and comprising walk, run, jump, turns, regressive movements and swings and it is suitable for this age that tends to express internal emotions together with varied and interesting music that helps encourage and suspense elderly people in performing exercises without feeling boredom and to ease tension featuring this age as well as discharging potential power freely. The results can be used in planning, following-up and evaluating programs of elderly people whether such programs for training or preventing from osteoporosis.

Research objective

To identify the effect of motor improvisation on:

1- The rate of concentration of adiponectin and osteocalcin and some related physiological variables represented by pulse, systolic and diastolic blood pressure, vital capacity, percentage of fat and body weight, body mass index (BMI) and percentage of blood cholesterol in elderly obese women.

2- Some physical variables represented by muscular strength (grip strength, strength of legs and forward vertebral column flexibility.

\section{Research hypotheses}

1- There are significant differences and rates of improvement between pre and post-measurements in rats of adiponectin and osteocalcin and in physiological variables under investigation in favor of the post-measurements.

2- There are significant differences and rates of improvement between pre and post-measurements in physical variables under investigation in favor of the post-measurements. 


\section{Research procedures}

\section{I- Method}

To achieve the research objectives and hypotheses the researcher used the experimental method with one of its designs by applying pre and postmeasurements to one experimental group to suit the nature of the research.

\section{Sample}

The researcher selected the sample intentionally from elderly women at Al-Sayeda Nafisa House for the Elderly. The sample individuals were (10) moderately obese women of (65 to 75 ) years of age. Homogeneity was made among individuals in all variables under investigation.

\section{Scientific coefficients for physical tests}

To find out stability coefficients the researcher tested and re-tested a sample of (8) elderly obese women from the research people but not from the research sample individuals under investigation with a time lag of (10) days before starting applying the program.

\section{Tools of collecting data}

\section{1- Devices}

- $\quad$ Restameter to measure height in $(\mathrm{cm})$ and weigh in $(\mathrm{kg})$.

- $\quad$ Seifganometer to measure systolic and diastolic blood pressures.

- A caliper to measure skin folds to determine proportion of body fat.

- A dynamometer to measure grip strength.

- A dynamometer to measure strength of legs .

- Figure Finder Flex tester to measure vertebral column flexibility.

- $\quad$ Elisa Reader to measure percentage of adiponectin and osteocalcin in blood (Attachment 7).

\section{2- Tools}

- A form to enroll data of the sample individuals.

- A form to register physiological and physical measurements and descriptive variables of the research sample (Attachment 3).

\section{3- Tests}

- $\quad$ To determine somatic composition by computing body mass index (BMI) (Attachment 7).

\section{4- Standard tables}

They are to determine percentages of body fat as established by Jackson and Pollock (2000) (Attachment 7).

\section{Motor improvisation program}

The objectives of this program were:

- To develop physiological aspects such as pulse, blood pressure, vital capacity, percentage of body fat, BMI, blood cholesterol and percentages of concentration of blood adiponectin and osteocalcin.

- $\quad$ To develop some physical aspects such as grip strength, strength of legs and vertebral column flexibility.

\section{Program time table}

Time was outlined for the program in the light of piloting opinion of experts (Attachment 4). The program was divided into (12) training units distributed to (12) weeks at the rate of one training unit a week including four lessons a week for (90) minutes each. Hence, the unit time took (6) hours a week meaning that the total program took (72) hrs, (Attachment 6).

The researcher selected motor improvisation for this age as it was varied (walk, run, jump, turns, regressive movements and swings). Also, it was suitable for this age that tends to express internal emotions together with varied and interesting music that helps encourage and suspense elderly people in performing exercises without feeling boredom and to ease tension featuring this age as well as discharging potential power freely.

\section{Pilot study}

The researcher conducted a pilot study before carrying out the research experiment on a sample of (8) women selected randomly from the same research people but not from the main research sample on Wednesday and Thursday, 1-2/8/2012. Stability and validity were carried out for physical tests on the same sample on Saturday, 4/8/2012. Tests were carried out once again with a time lag of (10) days i.e. on Monday, 13/8/2012.

\section{Research executive steps}

The research experiment was conducted in three steps as follows:

\section{a. Pre-measurement}

1- The pre-measurements that have been used in homogeneity of the experimental group were conducted in the period from Wednesday, 14/8/2012 to Friday, 17/8/2012.

\section{b. Execution of the research experiment}

The research experiment was executed at Al-Sayeda Nafisa House for the Elderly, Helwan in the period from Saturday, 18/8/2012 to Thursday, 8/11/2012 over (3) months at the rate of (12) training units distributed on (12) weeks by one training unit a week divided into (4) lessons a 
week and each lesson lasted (90) min. Hence, the unit lasted (6) hrs. a week i.e. (72) hrs. for the total program. Training was run on Saturday, Sunday, Tuesday, and Thursday weekly at (3.oo to 4.30) pm.

\section{c. Post-measurements}

At the end of applying the program, the researcher conducted the post-measurements for the research sample individuals in variables under investigation as followed in the pre-measurements from Saturday, 10/11/2012 to Tuesday, $13 / 11 / 2012$

II. :

\section{Statistical treatments}

They were run as suitable for the nature of the research by using the following:

- Arithmetic mean

- $\quad$ Standard deviation.

- $\quad$ Skewness coefficient.

- T-test of significance of differences.

- $\quad$ Spearman's correlation values.

Presentation of the research results and discussion:

I. Presentation of the research results

Table (1)

Arithmetic mean, standard deviation, significance of differences and percentage of improvement between means of the pre and post-measurements for the experimental group in all variables under investigation $\quad(n=10)$

\begin{tabular}{|c|c|c|c|c|c|c|c|c|c|}
\hline \multirow{2}{*}{ No. } & \multirow{2}{*}{\multicolumn{2}{|c|}{ Variables }} & \multicolumn{2}{|c|}{ Pre-measurements } & \multicolumn{2}{|c|}{ Post-measurements } & \multirow{2}{*}{ Deferences } & \multirow{2}{*}{ T-values } & \multirow{2}{*}{$\begin{array}{c}\text { Improvement } \\
\%\end{array}$} \\
\hline & & & M1 & S.D1 & M2 & S.D2 & & & \\
\hline \multirow{10}{*}{1} & \multirow{10}{*}{$\begin{array}{c}\text { Physiologica } \\
1 \text { variables }\end{array}$} & Pulse & 82.10 & 1.44 & 79.00 & 1.28 & 3.10 & $4.84 *$ & 3.77 \\
\hline & & $\begin{array}{l}\text { Systolic blood } \\
\text { pressure }\end{array}$ & 126.00 & 6.99 & 118.05 & 5.12 & 7.95 & $2.75^{*}$ & 6.30 \\
\hline & & $\begin{array}{c}\text { Diastolic blood } \\
\text { pressure }\end{array}$ & 81.10 & 0.78 & 79.59 & 0.99 & 1.51 & $3.59 *$ & 1.86 \\
\hline & & Vital capacity & 1339.53 & 31.35 & 1423.80 & 29.63 & 84.27 & $5.86^{*}$ & 6.29 \\
\hline & & Rate of body fat & 33.70 & 2.28 & 27.10 & 5.35 & 6.60 & $3.41 *$ & 27.85 \\
\hline & & Body weight & 86.30 & 8.06 & 77.13 & 3.79 & 9.17 & $3.10 *$ & 10.63 \\
\hline & & BMI & 34.80 & 1.89 & 32.06 & 1.06 & 2.74 & $3.80 *$ & 7.870 \\
\hline & & $\begin{array}{c}\text { Rate of blood } \\
\text { cholesterl }\end{array}$ & 232.10 & 14.3 & 18.90 & 13.35 & 51.20 & $7.93 *$ & 22.05 \\
\hline & & Adiponectin & 11.05 & 0.89 & 12.13 & 0.53 & 1.08 & $3.09 *$ & 9.77 \\
\hline & & Osteocalcin & 12.79 & 1.25 & 15.06 & 0.59 & 2.27 & $4.93 *$ & 17.75 \\
\hline \multirow{3}{*}{2} & \multirow{3}{*}{$\begin{array}{l}\text { Physical } \\
\text { variables }\end{array}$} & Grip strength & 7.42 & 1.50 & 12.25 & 2.01 & 4.83 & $5.75 *$ & 65.09 \\
\hline & & Strength of legs & 4.23 & 2.39 & 12.71 & 3.96 & 8.48 & $5.51 *$ & 200.47 \\
\hline & & $\begin{array}{l}\text { V. column } \\
\text { flexibility }\end{array}$ & 24.48 & 5.30 & 34.36 & 1.59 & 9.88 & *6.63* & 40.36 \\
\hline
\end{tabular}

Tabulated $\mathbf{t}_{0.05}=2.31$.

Data in Table (1) illustrate that there are statistically significant differences between the pre and postmeasurements for the research sample in favor of the postmeasurement in all physiological and physical variables under investigation. The percentage of improvement in physiological measurements ranged from ( $1.86 \%$ to $27.56 \%$ ) whereas those of physical measurements ranged from (40.36 to $200.47 \%$ ).

\section{Discussion of the results:}

The results will be discussed as per priority of the research hypotheses as follows:

\section{Discussing the results of variables related} to the $1^{\text {st }}$ hypothesis:

\section{1- Adiponectin hormone:}

Data in Table (1) demonstrate that there are statistically significant differences between the post and premeasurements in the percentage of adiponectin concentration in favor of the post-measurement as the value of " $t$ " (3.09) which is higher than the tabulated " $t$ " at (0.05) significance level. Also the results indicate that the percentage of variation of the postmeasurement for the pre-measurement for the same variable is $(9.77 \%)$ indicating that the program of motor improvisation had a positive effect on the adiponectin variable particularly when noticing percentages of body fat, body weight and BMI, which are increased in the post-measurements than the premeasurements. These results are in agreement with those achieved by Hissayo Yokama et al (2004) $)_{(46)}$ who achieved that variation in adiponectin had a close relationship with anthropometric variation motivated by an aerobic exercise and the weight loss noticed caused the levels of adiponectin to increase in sample suffering from obesity meaning that the exercise indirectly led to increasing adiponectin when the intervention was associated with weight or fat loss. 
Also the study of Fahim Abasi et al (2004) $)_{(45)}$ whose results confirmed that the weight loss noticed led to increasing the levels of adiponectin. The researcher attributed that to the weight loss and low body mass that helped improve the secretion of adiponectin that has positive effects in respect of the physiological aspect.

\section{2- Osteocalcin hormone:}

Results in Table (1) indicate that there are significant differences between the post and premeasurements in the percentage of concentration of osteocalcin in favor of the post-measurement as the value of " $t$ " (4.93) is higher than that of the tabulated at (0.05) level of significance. Also, the results illustrate that the percentage of variation of the post-measurement for the pre-measurement concerning the same variable amounts to $(17.75 \%)$ indicating that the motor improvisation program had a positive effect on the osteocalcin variable. Some studies illustrated that body weight and BMI were positively associated with bone density through several mechanisms that one of which is the relationship between the fatty tissue and bone metabolism and variation in some hormones secreted from the fatty tissue such as adiponectin and the relationship between body weight and the percentage of fat with bone metabolism through adiponectin reflects to the level of osteocalcin that is considered as an important indicator of bone metabolism (79). This made the researcher identify the percentage of osteocalcin that is considered as an indicator of bone density. Such studies are in conflict with the current study that in spite of the decrease in body weight, percentage of body fat and BMI and the increase in adiponectin as stated above, they do not affect the decrease in osteocalcin that is considered as an indicator of bone density. The results of the current studies agree with those of Said Al-Bawab et al $(2003)_{(76)}$ indicated that the level of osteocalcin in plasma reflected the range of the activity of osteoplast cells and the average of renewing the bone tissue. Also, the results of the current study are in harmony with those of J. Korean $(2010)_{(39)}$ and those of A. Guaadal $(2009)_{(39)}$ showed that osteocalcin had a pivotal role in regulating the relationship between the mass of fat and bone density and such role was affected by physical activities as in the increase in osteocalcin with various forms of physical activity. The results of the current study are in conformity with those of Pamela et al (2006) ${ }_{(65)}$ that regularity in physical programs in general led to increase indications of bone formation in plasma such as osteocalcin and basic bone phosphatase through the balance between the osteoplast cell activity and the osteoclast cells in favor of the osteoplast cells which agreed with those of the current investigation that regularity in the motor improvisation program led to increase osteocalcin concentration in plasma.

\section{3- Pulse}

The results in Table (1) show that there are significant differences between the post and premeasurements in pulse as it is decreased in the post-measurement as the value of "t" (4.84) which is higher than that of the tabulated at (0.05) confidence level. Also, the results in Table (4) indicate that the percentage of variation of the post-measurement for the pre-measurement for the same variable amounts to $(3.77 \%)$. The researcher referred that to the motor improvisation program that has a positive effect on the pulse variable. Such results are in agreement with those of Tariq Ali Ibrahim Rabie $(2008)_{(19)}$ who mentioned that pulse rate "heart rate" was one of the important scales and sensitive to the body as it expresses the exact number of heartbeats in a minute and for the elderly, the heart rate is low, which is not necessary for all individuals. The heart rate in rest ranges from (55 to 105) beats/min. and the muscular work leads to increase this rate that is also affected by age and sex. Farida Othman and Leiznight $(1999)_{(25)}$ indicated that a gradual program for cardio-respiratory system could lower heart rate during rest by about (10 to 15) beats $/ \mathrm{min}$. The heart rate varies according to the type of activity performed by the individual during the day. Abo Al-Ela Ahmed Abdel Fattah (1998) illustrated that the speed of heartbeats was increased during the exercise than during rest similar to the increase in blood volume pumped by the heart in a minute and during the exercise of low intensity the speed of heartbeats was increased greatly then decreased slightly when performing simply and finally stabilized at that level till the end of the athletic work. For the exercise of moderate intensity the speed of heartbeats was increased by the same rate but stabilized slowly according to oxygen consumption of tissues.

\section{4- Systolic and diastolic blood pressures:}

The results in Table (1) show that there are significant differences in the post and premeasurements in systolic and diastolic blood pressures in favor of the post-measurements as they are decreased in the post-measurements than in the pre-measurements as the value of " $t$ " in the systolic blood pressure is (2.75) whereas " $t$ " value in the diastolic blood pressure is (3.59) and those values are higher than those of the tabulated at (0.05) significance level. The results in Table (4) indicate that the percentage of variation of the 
post-measurement than the pre-measurement for systolic blood pressure is $(6.30 \%)$ whereas the percentage of variation for diastolic blood pressure is $(1.86 \%)$ and the researcher attributed that to the regularity in motor improvisation program as the right planning and regularity in execution in training programs represent the easiest way to achieve the goal which has a positive effect on systolic and diastolic blood pressures. That agree with Abo Al-Ela Ahmed Abdel Fattah (1998) who mentioned that blood pressure was an important indicator for the status of the circulatory system which illustrate the heart work and the vitality of its vascular. Hala Saqr $(2006)_{(32)}$ stated that the sport could lower hypertension due to the ability of sport to lose body weight. Iman Abdel Aziz and Segal Said (1993) $)_{(5)}$ mentioned that blood pressure was lowered greatly as the time of performance was increased for the aerobic program because the individual was conditioned leading to increase in the heart capacity and in turn, the amount of blood pumped was increased in a minute. Mohamed Al-Ekl (2004) 27$)$ clarified that systolic blood pressure was increased with age but the diastolic blood pressure was stopped at some limit and it was lowered after the age of fifty and that may be the reason for increasing the diastolic blood pressure in the elderly and he confirmed that the main factors behind the increase in blood pressure in the elderly were high level of body fat, diabetes and low motor activity. The researcher attributed the percentage of improvement in lowering systolic and diastolic blood pressures to the motor improvisation program that leads to lower percentage of body fat and weight.

\section{5- Vital capacity:}

The results in Table (1) demonstrate that there are significant differences between the post and premeasurements in vital capacity in favor of the post-measurement since the value of " $\mathrm{t}$ " is (5.86) which is higher than that of the tabulated at $(0.05)$ significance level. Also the results indicate that the percentage of variation of the post-measurement for the same variable amounts to $(6.29 \%)$ indicating that the motor improvisation program has a positive effect on vital capacity. Such results agree with those stated by Ahmed Nasr Al-Din (2003) who outlined that the increase in vial capacity could be attributed to aerobic exercises used in the program needed to specify the type of power to perform them for more than a few minutes to supply the body with power during the performance of exercises of respiration to pump oxygen to lungs for filtration to get into the blood and to cohesion with red cells where the blood retched with oxygen distributed to the operating muscles by heart and finally oxygen got into muscle cells carrying out the exercises. He added that muscles of the rib cage and diaphragm became stronger and joints of the rib cage became more flexible leading to increase the efficiency of lungs to stretch. Also in this age and by the effect of back muscle weakness the elderly bends forward and the earth gravity plays an important role in increasing such bend to impact on the rib cage and as a consequence, the rib cage became smaller and the chest muscles

Became weak. Performing the motor improvisation program helped improve muscular strength, vertebral column flexibility and back muscle strength leading to straighten and strengthen the rib cage and its muscles and in turn, vital capacity and the inspiration reserve volume were increased in comparison with exhalation air reserve. The current results tally with those of Sali Tawfiq $(2007)_{(15)}$ who achieved that the motor program used helped improve vital capacity in the elderly and with those of Manal Mohamed Sayed Sayed $(1994)_{(31)}$ who concluded that the suggested aerobic program assisted improve vital capacity in the elderly non performing sport. Also the study of Iman Abdel Aziz and Segal Said (1993)(5) indicated that the value of vital capacity was increased with time of performance.

\section{6- Percentage of body fat, body weight and BMI:}

The results in Table (1) demonstrate that there are significant differences between the post and premeasurements in percentage of body fat, body weight and (BMI) in favor of the postmeasurement as the post-measurements are decreased in comparison with the premeasurement and the value of " $\mathrm{t} "$ for the percentage of body fat, body weight and BMI are (3.41), (3.10) and (3.80) respectively and such values are higher than those of the tabulated at (0.05) significance level. The results indicate that the percentage of variation of the postmeasurement over the pre-measurement for the percentage of body fat, body weight and BMI are $(27.85 \%),(10.63 \%)$ and $(7.87 \%)$ respectively indicating that the motor improvisation program has a positive effect on such variables. Such results are in harmony with those of Baha'a Al-Din Ibrahim Salama $(2009)_{(8)}$ who indicated that the regularly physical physiological activity helped improve variations of the anti-body structure in the elderly as they helped reduce stocks of body fat and increase muscle mass. Also, Esam Badawi $(1998)_{(22)}$ confirmed that fat was more than carbohydrates as a source of energy in continuous aerobic exercises of moderate intensity for (20 to 30) min. and so the percentage and weight of body fat were reduced. 


\section{7- Percentage of blood cholesterol:}

The results in Table (1) illustrate that there are significant differences between the post and premeasurements in the percentage of blood cholesterol in favor of the post-measurement as the value of " $t$ " is (7.93) which is higher than that of the tabulated at (0.05) significance level. Also, the results indicate that the percentage of variation of the post-measurement over the premeasurement amounts to $(22.05 \%)$ and the researcher refers that to the motor improvisation program that caused the body weight and body fat to vary as the regularity in executing the motor improvisation program led to remove or mobilize from the internal layer of the blood vessel wall and that in turn prevented sclerosis such finding agreed with that of Mcardle William, et al (1991) $_{(61)}$ who indicated that bad cholesterol was mobilized and carried away from the artery internal wall and delivered to the liver for decomposition and excretion by bile and the body got rid of it through the gut. The same finding corresponded with that of Higuchin (1994) $(47)$, Khadra Eid $(1999)_{(11)}$ and Wafaa Al-Sayed Mahmoud (2000) $)_{(11)}$ who concluded that the physical exercise showed a significant improvement in body fat by decreasing low density cholesterol and in turn, supporting directly the results of the current study.

Therefore, the validity of the $1^{\text {st }}$ hypothesis stating "there are significant differences and rates of improvement between the pre and postmeasurements in percentage of concentration of adiponectin and osteocalcin hormones and in physiological variables under investigation in favor of the post-measurement", is established.

II. Discussing the results of variables related to the $2^{\text {nd }}$ hypothesis:

\section{Muscular strength and forward vertebral column flexibility:}

The results in Table (1) illustrate that there are significant differences between the post and premeasurements in physical variables viz. grip strength, strength of legs and forward vertebral column flexibility in favor of the postmeasurement as the post-measurements are increased over the pre-measurements since the " $\mathrm{t}$ values for grip strength, strength of legs and forward vertebral column flexibility are $(5.75 \%)$, $(15.51 \%)$ and $(6.63 \%)$ respectively and such values are higher than those of the tabulated at (0.05) significance level. Also, the results show that the percentages of variation of the postmeasurement over the pre-measurement for grip strength, strength of legs and forward vertebral column flexibility are $(6.63 \%),(200.47 \%)$ and $(40.36 \%)$ respectively indicating that the motor improvisation program has a positive effect on physical variables viz. muscular strength and flexibility. Such results are in agreement with those of Bahaa Al-Din Ibrahim Salama $(2009)_{(8)}$ who stated that variations occurred in the body structure and characteristics with age affecting flexibility of joints due to the strain of muscle tissues and muscle ends associated with bones generally known in the elderly as a consequence of low chemical and physical activity in the elderly. However, it has been confirmed that the performance of physical exercises helped improve the level of flexibility and enable muscles and joints to gain more power to contract and to relax particularly if the physical program considered muscle stretch and extension exercises and increasing the range of motor exercises given to the elderly. Also, it has been shown that regular physical and physiological exercises enabled the elderly to improve anti-body structure variations as they helped the elderly lower fat stocks and increase muscle mass. The current results are in line with those of Zaki Mohamed Mohamed Hassan $(2007)_{(13)}$ who found that the exercise caused a variation in the percentage of distribution of muscle fibers with age, however, it was possible to increase the number of slow fibers on account of the transformation of some fast fibers. Among studies Mofti Ibrahim (2004) $)_{(30)}$ stated that interval exercises led to improve muscle strength and endurance greatly and aerobic exercises helped strengthen muscles of the lower limbs due to the increase of muscle mass. Such finding was verified by Ezz Al-Din Abdel Wahab Hassan $(2000)_{(21)}$ who concluded that the therapeutic exercise program helped develop trunk flexibility and the leg muscle strength. Also the study of Samia Abdel Rahman Othman (1994) $)_{(16)}$ stated that the aerobic exercise program helped increase back and leg muscle strength and develop vertebral column and body muscle flexibility.

Therefore, the validity of the $2^{\text {nd }}$ hypothesis stating "there are significant differences and rates of improvement between the pre and postmeasurements in physical variables under investigation in favor of the post-measurement", is established.

\section{Conclusions:}

In the light of the research objectives and hypothesis and on the basis of the results of statistical treatments the researcher concluded the following:

1- The motor improvisation program for the category of elderly women has a positive effect on loosing 
body weight leading to increase the percentage of concentration of adiponectin in blood.

2- The motor improvisation program for the category of elderly women has a positive effect on increasing the concentration of osteocalcin in blood leading to maintain their bone density.

3- The motor improvisation program for the category of elderly women has an effect on pulse rate and systolic and diastolic blood pressures, vital capacity, percentage of body fat, body weight and the level of cholesterol in blood in such women.

4- The regularity in the motor improvisation program helps improve some physical variables such as increasing grip strength, strength of legs and forward vertebral column flexibility.

\section{Recommendations:}

On the basis of the research results and conclusions the researcher recommends the following:

1- Carrying out the motor improvisation program, the research topic, on elderly women attended the elderly houses which may represent a therapeutic and protective means of obesity and osteoporosis.

2- Making use of the motor improvisation program to improve the level of adiponectin and osteocalcin in elderly women to maintain weight and bone density.

3- The state should consider the elderly sport, take care of them through governmental and national establishments and spread sports awareness in such establishments.

4- Establishing a motor improvisation program for different ages and samples that may strongly need such program.

\section{References}

\section{Arabic references:}

1- $\quad$ Abo Al-Ela Ahmed Abdel Fattah (1998): "Biology of Sport", Cairo.

2- Iglal Mohamed Ibrahim, Nadia Darwish (1997) "Modern Creative Dance", Dar Al-Hana, Cairo.

3- Ahmed Nasr Al-Din Sayed (2003): "Theories and Applications of Physiology of Sport", Arab Thought House, $1^{\text {st }}$ Ed.

4- Amal Sayed Morsi (2001): "Effect of motor improvisation on embarrassment and sel-confidence in girls in prep school (adolescence), Scientific Journal, No. 3, Faculty of Physical Education, Port Said, Suez Canal University.

5- Iman Abdel Aziz, Sigal Said (1993): Effect of a Yoga program by using Pharaonic movements on some physiological variables and psychological traits in women. Journal of Sciences and Arts of Sport, Vol. 5, No. 1, Helwan University.

6- Aiman Al-Husseini (1992): "Obesity", Teenagers House.

7- Baha'a Al-Din Salama (2002): "Sports Health and Physiological Limits for Physical Activity", Arab Thought House, $1^{\text {st }}$ Ed.

8- Baha'a Al-Din Salama (2009): "Physiology of Physical Effort", Arab Thought House, $1^{\text {st }}$ Ed.

9- Jehan Galal Al-Tayeb (1999): Effect of a therapeutic protective program on weight loss in women, M.Sc.Thesis, Faculty of Physical Education for Girls.

10- Hussein Ahmed Heshmat, Nader Mohamed Shalabi (2003): "Physiology of Muscular Fatigue", Book Center, Cairo.

11- Khadra Eid Mohamed Ibrahim (1999): Effect of a suggested motor program for weight loosing on physical efficiency, some somatic measurements and blood fats in women pre and post-menopause. Ph.D. Thesis in Physical Education.

12- Reda Rashad (1998): A comparative study on bone density and some variables associated between performers and non-performers of physical activities in post-menopause, $\mathrm{Ph}$. D. Thesis (unpublished), Faculty of Physical Education, Zagazig.

13- Zaki Mohamed Mohamed Hassan (2007): "Descriptive Functional Anatomy of Muscle Strength Exercises", Alex. University, Egyptian Library for Printing and Publishing.

14- Zakia Ahmed Fathi, Maha Khalil Mohamed (2006): "Physiology of Sport between the Theory and Application", Cairo.

15- Sali Tawfiq Zakaria Hegazi (2007):Effect of a suggested varied motor program on improving some physiological and psychological variables in the elderly, Faculty of Physical Education for Girls, Cairo.

16- Samia Abdel Rahman Othman (1994): Effect of therapeutic exercises for backache in personnel at Culture Palaces Authority, Faculty of Physical Education for Girls, Cairo.

17- Scientific Studies Series (1986): "Loose Your Weight without Regime", Education Library, Beirut.

18- Safia Ahmed Mohiy Al-Din (2007): "Creative Design of Motor Expression Shows", Al-Anglo Egyptian Library, Cairo.

19- Tariq Ali Ibrahim Rabie (2008): "Physiology of the Elderly Sport", Dar Al-Wafaa, $1^{\text {st }}$ Ed., Alex. University. 
20- Ezz Al-Din Al-Dishnary (1991): "Sport and Medicine, Bilateral Relationship and Positive and Negative Effects", Dar Al-Marikh.

21- Ezz Al-Din Abdel Wahab Hassan Al-Kordi (2001) Effect of a suggested exercises program to treat lower backbone pains on trunk flexibility and strength of abdominal and back muscles of males of 35 to 45 yrs., Faculty of Physical Education for Girls, Cairo.

22- Essam Badawi (1998):"Sport is a Panacea", Arab Thought House, Cairo.

23- Afaf Abdel Monem Darwish, Mohamed Jaber Braika (2000): "Movement and the Elderly", Knowledge Facility, Alexandria.

24- Farouq Al-Sayed Abdel Wahab (1983): "Principles of physiology of Sport", Book House, Cairo.

25- Farida Othman, Liznight (1999): "Physiology of Sport and Recording Heartbeats", Pen House, Cairo.

26- Lila Sharaf Al-Din (2006): Motor improvisation by using stimuli and it effect on motor creativity and some psychological variables. Ph. D. Thesis (unpublished), Faculty of Physical Education, Helwan University, Cairo.

27- Mohamed Al-Ekl (2004): "The Elderly, Variations, Symptoms, Prevention and Treatment", Al-Helal House for Printing, Cairo.

28- Mohamed Helmi Al-Ganini (2008): Effect of the sport of Walking on bone density in performers and non-performers. M.Sc. Thesis (unpublished), Faculty of Physical Education, Tanta University.

29- Mohamed Sobhi Hassanein (2000): "Measurement and Evaluation in Physical and Sports Education", Arab Thought House, Part 1, Cairo.

30- Mofti Ibrahim (2004): "Physical Fitness the Way to Health and Championship", Arab Thought House, $1^{\text {st }}$ Ed., Cairo.

31- Manal Sayed Sayed Ahmed Mansour (1994): Effect of a suggested aerobic dance program on some biological systems and muscle groups in non-sport performers in the stage of gradually lowering body functions. M.Sc. Thesis (unpublished), Faculty of Physical Education for Girls, Cairo.

32- Hala Saqr (2006): "High and Low Blood Pressure", Teenagers House, Cairo.

33- Hala Farghali Kamel Menazea (1996): A suggested sports program for the elderly and its effect on blood fats and social adaptation. M.Sc. Thesis, Helwan University, Cairo.

34- Hala Yahia Al-Sayed Hegazi (2004): Effect of a program of exercises with weights on bone density and some associated factors in women of 35 to 50 years of age. Ph. D. Thesis (unpublished), Faculty of Physical Education, Zagazig University.

35- Wafaa Al-Sayed Mahmoud (2000): Effect of physical effort caused oxidation tension on some biochemical variables in females in different two ages. Scientific Journal, Faculty of Medicine, Zagazig University.

\section{Foreign references:}

36- Allen W., Jackson, et al (2004): Physical Activity for \& fitness, Human Kinetics, USA.

37- Archer M.C. Mc Henry EW, Word WE,(2008): " Adiponectin is Ametabolic Link Between obesity and Bone Mineral Density", Patient Public Health Professional.

38- Arita Y., Kihara S., Ouchi., et al.(1999): Paradoxical decrease of an adipossespecific protein, adiponectin in obesity. Biochem. Biophys. Res. Commun 257:79-83.

39- A. Guadalupe - Grou, et al(2009): Strength Training Combined with Plyometric Jumps in adults: sex differences in fat - bone axis adaptations.

40- Ceicl-text book of Medicine, $21^{\text {st }}$, Edition disorders Metabolism: 1090-1094.

41- David J., Anspaugh, Michael H., Frank D., Rosato. (2007): Concepts and Applications. Third edition, human kinetick, USA.

42- Department of Epidemiology and statistics, school of public Health, central south University, Xiangya Road, hangsha, Hunan, China (2007):" Relationships between serum adiponecthn, leptin, resistin, visfatin levels and bone biochemical markers in Chinese men".

43- Diabetes (2004): American Diabetes Association, Inc.

44- Erikson, EF, Osteoporosis (1992): "Pathogenesis and Treatment, therapy manual", Denmark, Novo Nordisk.

45- Fahim Abbasi., James W. Cindy Lamendola., Tracey McLaughlin., et al. (2004): Discrimination Between Obesity and Insulin Resistance in the Relationship With Adiponectin, vol. 53, March.

46- Hissayo Yokoyama., et al. (2004): Effect of Aerobic Exercise on Plasma Adiponectin Levels and Insulin Resistance in Type 2 Diabetes. American diabetes, Inc.

47- Highuchi., M, Hashicaota., T., Yamakawa, K., et al (1994): Effects of exercise training on plasma high density lipoprotein cholesterol level at constant weight, clinical-physiology.

48- Hotta K., Funhashi., et al. (2000): Plasma concentration of a novel adipose-specific protein, 
Adiponectin in type2. arterioscler, Thromb, Vasc. Biol; 20:1595-99.

49- HUE ling $\mathrm{P}$, spiegelman BM: Adipo is anoval adipose specific gene dysregulated in obesity J. Biol chem., 271:10697-10.

50- Jaak Jurima and Toivo Jurimae; plasma adiponectin concentration in healthy pre-and postmenopausal women (2006): relationship with body composition, bone mineral, and metabolic variables.

51- J. Bone Miner Res, Manuscript (2010): " adiporectin and its association with bone mass accula in Childhood", 25 (10): 2212.

52- Jurimae, J. and Jurimae, T (2008): " Bone Metabolism in Young female Athletees.

53- Jurimae J, Jurimae T.(2007): " Plasma adiponectin concentration in healthy pre-and postmenopausal women, relationship with body composition, bone mineral and metabolic variables", Am J Physiol Endocrinol Metab 293: E42-E47.

54- J.B. Richards, A.M. Valdes, et al(2007): " Serum Adiponectin and Bone Mineral Density in Women", 92(4): 1517.

55- J- Rim, J, Kumst, et al(2009):" Adipocy to kine and ghrelin levels inrelation to bone mineral density in physically active older women: Longitydinal associations.

56- J-Korean Med Sci(2010): " Effects of Body Compositin leptin, and adiponectin on Bone Mineral Density in Prepubrtal Girls".

57- Kadowaki T; Yamauchi T; Kybota et al(2006): " Adiponectin receptors in insulin resistancem diabetes, and the metabolic syndrome", J. Clin. Invest; 116:1784-92.

58- Lian JB, Tassihari M, Glowecki J(1984): "Resorption of Implanted bone prepared from normal and warfarin- treated rats", J. Clin Invest 73: 1223.

59- $\quad$ Linn Goldberg., Diane Elliot (2000): The Healing power of Exercise.

60- Lourdes Basurto et al(2010): " Adiponectin S associated with low bone mineral density in elderly men", Endoctine Research unit 2 Department of Radiology, National Medical Center.

61- Mcardle, William D. et al (1991): Exercise physiology energy, Nutrition, and Human Performance, $3^{\text {rd }}$, edit, Lea and Febiger, (USA).

62- Minisola S, Rosso R. Romagnoli E, D, Erasmo E, Manfredi G, Damiani Cde Antoni F, Mazzuoli G.(1997):" Serum Osteocalcin and Bone mineral density at various skeletal sites": a study performed with three different assays. J. Lab Clin Med, 129:422-29.
63- Numos Katayama Y, et al(2011): Influence of acute aerobic exercise on adiponectin oligomer concentrations in middle - aged abdominally obese men. "Metabolism, 60 (2): 186-94.

64- Numos, Suzuki M, et al(2008): "Effects of acute aerobic exercise on high - molecular wiehgt adiponectin, "Medsci Sports Exorc 40(7): 1271-6.

65- Pamela S, Rector R.S. et al (2006): Weight bearing aerobic exercise increases markers of bone formation during short-term weight loss in overweight and obese men and women", Metabolism clinical and experimental (55), 1616-1618.

66- Peichl P, Griesmacher A, Muller MM, Mareau R, Kumpan W. Brool H. (2000).

67- Said A- El Bawab et al (2003): Effect of Smoking on Calcium Regulating Hormones", Department Faculty of Medicine for (Boys \& Girls) Al Azhar University.

68- Schneer Geargette (1994): "Movement improvisation in the world of Ateacher and Her students", Canada: Human Kinetices.

69- Stefan N. and Stumvoll MM (2002): " Adiponectin its role in metabolism and beyond", Horm, Metab, Res; 34:469-74.

70- Teruhiko Kondo., Masami Murakami (2006): Effect of Exercise on circulation Adipokine level in obese young woman. Department of clinical. Endocr J., Vol. 53; No.2. 189-195.

71- Welsh, L \& Rutherford, O(1996): European Journal of applied-physiology-and occupational- physiology (Berlin); 74 (6), Dec 511 refs: 27.

72- William N. Kelly(2001): text book of Rheumatology, $6^{\text {th }}$ Ed, Library of congress, 2001.

73- Young- Jum et al(2009): " Integrative Physiology Defined Noval Metabolic Roles of Osteocolcin", The Korean Academy of Medical Sciences.

\section{Internet:}

74- $\quad$ www.almasryalyoum.com/nod/1146781.

75- www.Answer.com./adiponectin information.htm

76- www.bbc-co.uk/arabic/multimedia/2012110/121001. oldpopulation.people.shtml.

77- http://www.Dslabs.com

78- http://dolly;biochem.Arizona.edu/Bioc462b/Honors/ eshipley/background.Htm.

79- http://forum.iraqacad.org/viewtopic.php? $\mathrm{f}=40 \& \mathrm{t}=32$ $\underline{5-}$

80- $\quad$ www.lbasurtoa@yahoo.com. 
